TITLE:

\title{
Single-phase hexagonal GaN grown on AlAs/GaAs(001)
}

\section{AUTHOR(S):}

Funato, M; Ishido, T; Hamaguchi, A; Fujita, S; Fujita, $\mathrm{S}$

\section{CITATION:}

Funato, M ...[et al]. Single-phase hexagonal GaN grown on AIAs/GaAs(001). APPLIED PHYSICS LETTERS 2000, 77(2): 244-246

\section{ISSUE DATE:}

2000-07-10

URL:

http://hdl.handle.net/2433/39636

\section{RIGHT:}

Copyright 2000 American Institute of Physics. This article may be downloaded for personal use only. Any other use requires prior permission of the author and the American Institute of Physics. 


\title{
Single-phase hexagonal GaN grown on AIAs/GaAs(001)
}

\author{
Mitsuru Funato, ${ }^{\text {a) }}$ Teruki Ishido, Atsushi Hamaguchi, Shizuo Fujita, and Shigeo Fujita \\ Department of Electronic Science and Engineering, Kyoto University, Kyoto 606-8501, Japan
}

(Received 18 April 2000; accepted for publication 23 May 2000)

\begin{abstract}
This letter describes successful growth of single-phase hexagonal GaN ( $h-\mathrm{GaN}$ ) layers on cubic $\mathrm{GaAs}(001)$ nominally singular substrates with the assistance of thin AlAs intermediate layers. The crystallographic relationship between $h-\mathrm{GaN}$ and $\mathrm{GaAs}$ is extracted from a pole figure to be $h-\mathrm{GaN}[0001] \| \mathrm{GaAs}[001]$ in the growth direction and $h-\mathrm{GaN}[10 \overline{1} 0] \| \mathrm{GaAs}[1 \overline{1} 0]$ in the in-plane direction. In a photoluminescence spectrum measured at $20 \mathrm{~K}$, excitonic emission from the $h$-GaN layer is detected at $3.47 \mathrm{eV}$. (C) 2000 American Institute of Physics. [S0003-6951(00)05328-6]
\end{abstract}

$\mathrm{GaN}$, which is now in practical applications in the field of optoelectronics, has mostly been grown on sapphire(0001) substrates. ${ }^{1}$ On the other hand, there is an increasing interest in other substrates such as $\mathrm{Si}$ and GaAs because of the larger wafer size, higher conductivity, and advanced technology of these substrates. ${ }^{2-8}$ Among a number of candidate substrates, GaAs possesses an advantage from the viewpoint of the thermal expansion coefficients; the thermal expansion coefficients of GaAs and $\mathrm{GaN}$ are $5.7 \times 10^{-6}$ (Ref. 9) and 5.59 $\times 10^{-6} \mathrm{~K}^{-1},{ }^{10}$ respectively. The difference between them is much smaller than those with other substrates such as $\mathrm{Si}$, 3C-SiC, and sapphire, which may prevent the generation of cracks. This encourages us to use GaAs as a substrate for the $\mathrm{GaN}$ growth. There have already been many reports on the growth of hexagonal $\mathrm{GaN}(h-\mathrm{GaN})$ and cubic $\mathrm{GaN}(c-\mathrm{GaN})$ on the GaAs substrates. ${ }^{4-8}$ Basically, $h-\mathrm{GaN}$ is grown on $\mathrm{GaAs}(111)$ and $c-\mathrm{GaN}$ is grown on $\mathrm{GaAs}(001)$ as is deduced from the crystallographic relationship. In contrast, this letter demonstrates that $c$-oriented $h$ - GaN is grown on $\mathrm{GaAs}(001)$ if an AlAs thin layer is inserted between $\mathrm{GaN}$ and $\mathrm{GaAs}(001)$. Since the lattice parameters of GaAs and AlAs are almost the same, and since no remarkable difference in their surface structures has been seen, the observed result is interpreted by the difference of the surface chemistry of GaAs and AlAs.

The samples were grown by atmospheric-pressure metalorganic vapor phase epitaxy. On the GaAs(001) substrate, a 20-nm-thick AlAs layer was grown at $700{ }^{\circ} \mathrm{C}$ using trimethylaluminum (TMAl) and tertiarybutylarsine (TBAs) as source precursors. The molar flow ratio of TBAs/TMAl was 10 and the growth rate was $900 \mathrm{~nm} / \mathrm{h}$. Atomic force microscopy (AFM) observation proved that the surface structure of AlAs thus obtained was quite similar to that of GaAs and consisted of monolayer steps $(\sim 0.3 \mathrm{~nm})$ and atomically flat terraces. Therefore, the influences of the surface structures on the crystalline structures of $\mathrm{GaN}$ can be neglected in this study. Then, $0.3-\mu \mathrm{m}$-thick $\mathrm{GaN}$ was successively grown using triethylgallium (TEGa) and dimethylhydrazine (DMHy). The growth was initiated by simultaneously supplying those precursors to avoid nitridation, which may affect surface structures and influence the crystalline structure. ${ }^{6}$ The growth temperature was ranged from 500 to $700^{\circ} \mathrm{C}$, at which deg-

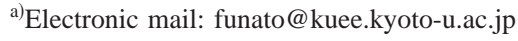

radation of the AlAs surfaces does not occur. The typical molar flow ratio of DMHy/TEGa was 100 and the growth rate was $280 \mathrm{~nm} / \mathrm{h}$.

First of all, $\mathrm{GaN}$ was grown directly on the $\mathrm{GaAs}(001)$ substrate. It was confirmed by x-ray diffraction measurements using $\mathrm{Cu} K \alpha_{1}$ radiation as an x-ray source that the $\mathrm{GaN}$ layers were in the cubic phase with $c-\mathrm{GaN}[001] \mid \operatorname{GaAs}[001]$, though the inclusion of the hexagonal phase could not completely be eliminated. This is similar to many past reports. ${ }^{6-8}$ On the other hand, when an AlAs thin layer $(20 \mathrm{~nm})$ was inserted between the GaAs substrate and $\mathrm{GaN}, \mathrm{GaN}$ was no longer in the cubic phase but in the hexagonal phase with the orientation relation of $h$-GaN[0001] |GaAs[001], which was assessed by the following manner. Figure 1 shows an x-ray diffraction pole figure of $\mathrm{GaN}$ grown on $\mathrm{AlAs} / \mathrm{GaAs}(001)$ at $600^{\circ} \mathrm{C}$. In the figure, $\chi$ refers to the angle between the GaAs surface $[(001)$ plane] and the plane under measurement. The diffractions from $h-\operatorname{GaN}\{10 \overline{1} 1\}, c-\operatorname{GaN}\{002\}$, and $\operatorname{GaAs}\{115\}$ planes were measured successively without changing the experimental configurations. As a result, the six-fold $h$-GaN $10 \overline{1} 1$ diffractions were detected at $\chi=62^{\circ}$, but no $c$-GaN 002 dif-

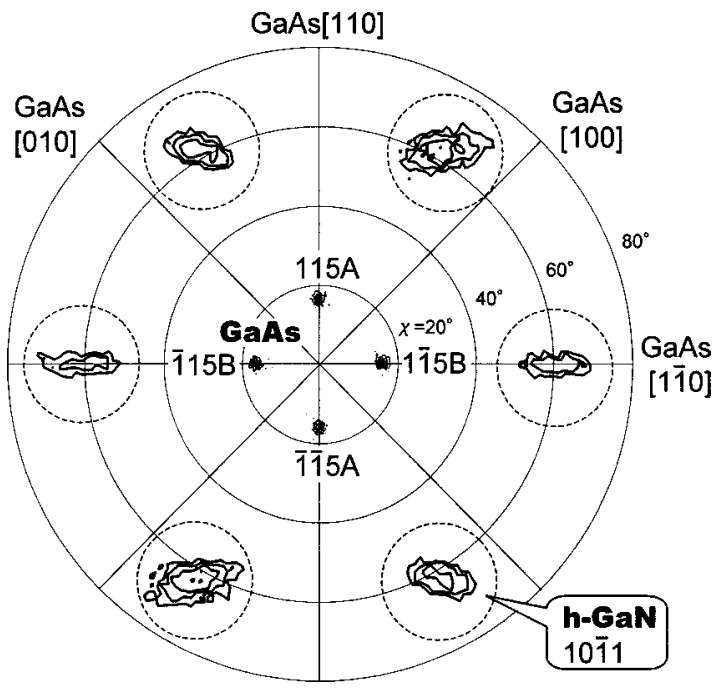

FIG. 1. Pole figure of $\mathrm{GaN}$ grown on $\mathrm{AlAs} / \mathrm{GaAs}(001)$ at $600{ }^{\circ} \mathrm{C}$. The diffractions from $h-\mathrm{GaN}\{10 \overline{1} 1\}, c-\mathrm{GaN}\{002\}$, and $\operatorname{GaAs}\{115\}$ planes were measured successively without changing the experimental configurations and all results are shown together. Isointensity contour levels at $2^{n}$ ( $n$ $=0,1,2,3, \cdots)$ cps. 


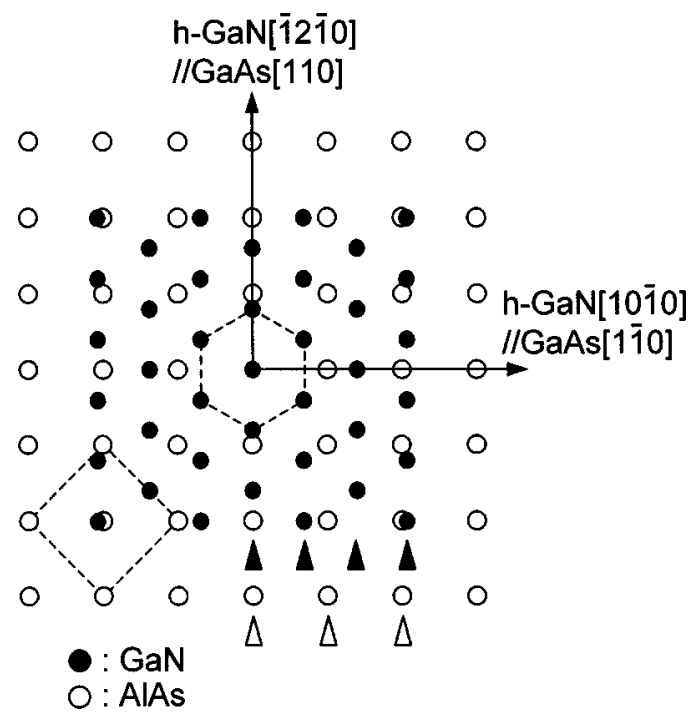

FIG. 2. Schematic view of the in-plane crystallographic relationship in GaN/AlAs/GaAs(001). Hexagon and square indicated by the dotted lines represent $h-\mathrm{GaN}$ and cubic GaAs lattices, respectively. Closed arrowheads designate the $h-\mathrm{GaN}(10 \overline{1} 0)$ planes, while open arrowheads the $\operatorname{GaAs}(1 \overline{1} 0)$ planes.

fractions. Two important conclusions can be extracted from these results: (1) the grown film is single-phase $h-\mathrm{GaN}$ and (2) its $c$ axis is parallel to the $\operatorname{GaAs}[001]$ direction (i.e., growth direction). The latter was extracted in the following way. The observed value of $\chi$ indicates that the angle between the $h-\mathrm{GaN}\{10 \overline{1} 1\}$ planes and the $\operatorname{GaAs}(001)$ plane is $62^{\circ}$. On the other hand, a plane in $h$-GaN forming an angle of $62^{\circ}$ to $\{10 \overline{1} 1\}$ is (0001). Therefore, $h-\mathrm{GaN}(0001)$ is parallel to $\operatorname{GaAs}(001)$, that is, $h-\mathrm{GaN}[0001] \mid \operatorname{GaAs}[001]$. Further information obtained from the pole figure is that the GaAs $\overline{1} 15 \mathrm{~B}$ and $1 \overline{1} 5 \mathrm{~B}$ diffractions and two GaN $10 \overline{1} 1$ diffractions are on a straight line. This provides the additional conclusion that a pair of parallel $h$-GaN $\{10 \overline{1} 0\}$ planes

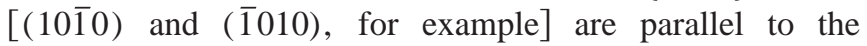
$\operatorname{GaAs}(\overline{1} 10)$ and $(1 \overline{1} 0)$ planes.

By summarizing the results of the pole figure measurement, the in-plane crystallographic relationship involved in GaN/AlAs/GaAs(001) can schematically be drawn as Fig. 2. Since the AlAs layer is sufficiently thin to grow coherently, lattice points are exactly the same as those in GaAs. As seen, $h$-GaN $[\overline{1} 2 \overline{1} 0] \| \mathrm{GaAs}[110]$ as well as $h$-GaN[1010]||GaAs[110] is satisfied, which is a desirable configuration because those four planes can be cleaved. Now, a question arises what causes such a crystallographic relationship. We consider that a reason is strain. Twice the $\operatorname{GaAs}\{110\}$ spacing $[=7.9950 \AA$ at room temperature (RT)] is well commensurate with three times the $h-\mathrm{GaN}\{10 \overline{1} 0\}$ spacing ( $=8.2853 \AA$ at RT), which is indicated by arrowheads in Fig. 2. Therefore, the epitaxial relationship takes place so as to make those planes parallel, while minimizing the strain. ${ }^{11}$ Geometrically, $h$-GaN $[10 \overline{1} 0]|| \operatorname{GaAs}[110]$ is equivalent to $h-\mathrm{GaN}[10 \overline{1} 0] \| \operatorname{GaAs}[1 \overline{1} 0]$, but the former did not occur. This is probably due to the anisotropic bond configuration of AlAs; for the (001) surface of AlAs, the orientation of the $\mathrm{Al}$ dangling bonds has projection along [110], while that of the As dangling bonds has projection along $[1 \overline{1} 0]$, which suggests that the bonds between $\mathrm{Al}$ and $\mathrm{N}$ Downloaded 30 May 2007 to 130.54 .110 .22 . Redistribution subject

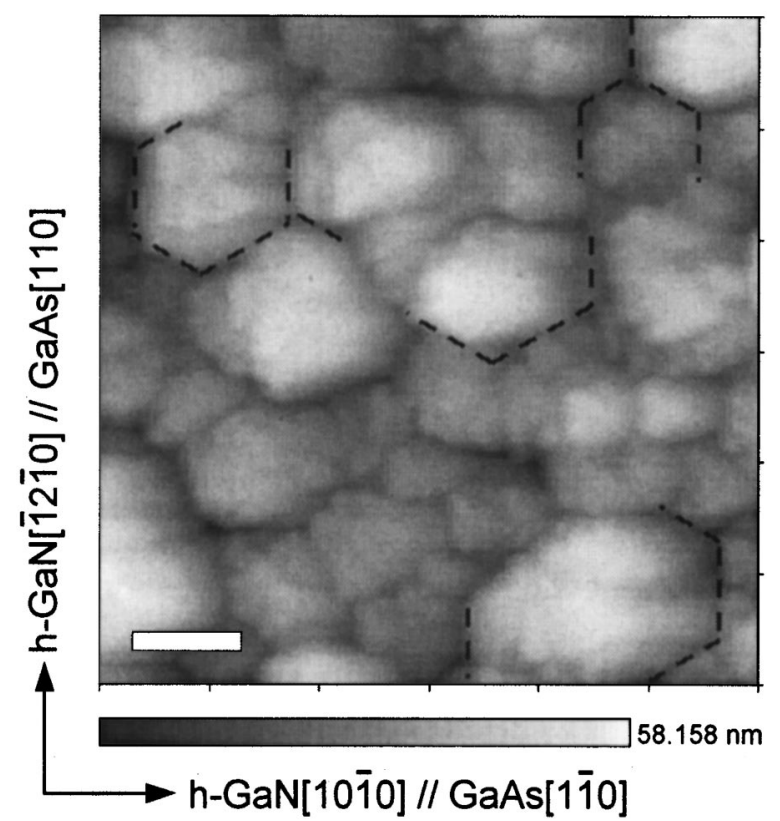

FIG. 3. Surface AFM image of $h$-GaN grown on AlAs/GaAs(001). The dotted lines were drawn so as to be parallel to the sides of the hexagon in Fig. 2. Marker represents $100 \mathrm{~nm}$.

align nitrogen atoms along $\operatorname{AlAs}[110]$ and lead to

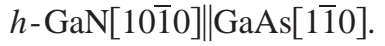

This crystallographic relationship is reflected on the surface. Figure 3 shows an AFM image of $h$-GaN grown on AlAs/GaAs. Many hillocks are observable. The dotted lines in the figure were drawn so as to be parallel to the sides of the hexagon in Fig. 2. Relatively good agreement between the dotted lines and the sides of the hillocks suggests that those consist of $h-G a N\{10 \overline{1} 0\}$ planes. Since $\{10 \overline{1} 0\}$ is a singular plane of hexagonal crystals, that may appear at the growth front and, consequently, the sides of the hillocks became parallel to $\{10 \overline{1} 0\}$.

The experimental finding that the crystalline structures of GaN varied depending on the underlying layers is analogous to $\mathrm{Cd}(\mathrm{Mn}) \mathrm{Te}$ on GaAs. ${ }^{12-14}$ On a clean GaAs(001) substrate, [111]-oriented CdTe is grown with the crystallographic relationship of CdTe[211]| $\operatorname{GaAs}[110] .{ }^{13}$ Since cubic $\{111\}$ planes are equivalent to hexagonal $\{0002\}$ planes, the crystallographic relationship in $\mathrm{CdTe} / \mathrm{GaAs}(001)$ is the same as that in $h$-GaN/AlAs/GaAs(001) revealed here. In contrast, on a $\operatorname{GaAs}(001)$ substrate whose surface is perturbed in some way, [001]-oriented CdTe is grown. This perturbation could be the result of a very thin layer of residual oxide ${ }^{13}$ for example, or the presence of a monolayer of adsorbed Te. ${ }^{14}$ What the examples of $\mathrm{Cd}(\mathrm{Mn}) \mathrm{Te} / \mathrm{GaAs}(001)$ tell us is that the surface electronic states of an underlying layer play a crucial role in determining the crystalline orientation of the "epitaxial" layer. Actually, in this study, both the AlAs and GaAs surfaces were atomically flat, and furthermore, nitridation which can modify the surface structures was not conducted, as mentioned previously. Therefore, the present result that $c-\mathrm{GaN}$ is grown on $\mathrm{GaAs}(001)$, while $h-\mathrm{GaN}$ on $\mathrm{AlAs} / \mathrm{GaAs}(001)$ must be interpreted in terms of the difference in chemistry of the GaAs and AlAs surfaces. Another interesting experimental result we found is that $h-\mathrm{GaN}$ can be grown even on AlAs covered with thin $(<5 \mathrm{~nm}) \mathrm{GaAs}$ to AIP license or copyright, see http://apl.aip.org/apl/copyright.jsp 


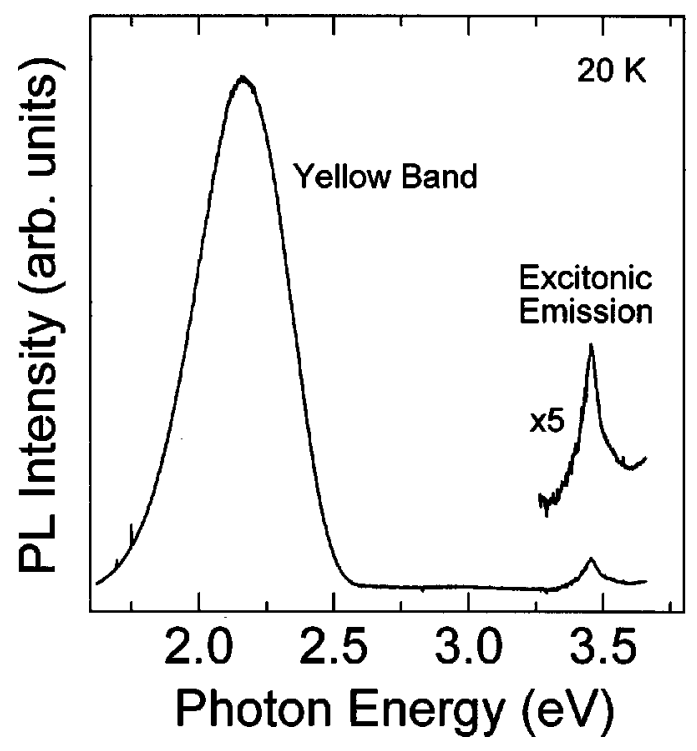

FIG. 4. PL spectrum of $h$-GaN grown on $\mathrm{AlAs} / \mathrm{GaAs}(001)$ at $900^{\circ} \mathrm{C}$. The measurement was carried out at $20 \mathrm{~K}$ under the excitation by a $\mathrm{He}-\mathrm{Cd}$ laser.

(the details will be given elsewhere). ${ }^{15}$ On the basis of those results, we consider that the surface electronic structure determines the crystalline phase and orientation of GaN and that the interface atom itself is not essential.

Finally, the photoluminescence (PL) properties of $h$-GaN on AlAs/GaAs(001) are shown. The measurements were conducted at $20 \mathrm{~K}$ with a $\mathrm{He}-\mathrm{Cd}$ laser $(325 \mathrm{~nm})$ as an excitation source. PL was detected using a cooled charge coupled device in conjunction with a $50 \mathrm{~cm}$ monochromator. In the earlier discussions, $\mathrm{GaN}$ has been grown at relatively low temperatures $\left(500-700^{\circ} \mathrm{C}\right)$ in order to avoid degradation of the AlAs surface. Howerver, those layers did not exhibit PL. Therefore, on such GaN, whose thickness was reduced to $20 \mathrm{~nm}, 1.1-\mu \mathrm{m}$-thick $\mathrm{GaN}$ was grown at a higher temperature. ${ }^{16}$ Tentative (not optimized) growth conditions were a growth temperature of $900{ }^{\circ} \mathrm{C}$, a V/III ratio of 25 , and a growth rate of $1.1 \mu \mathrm{m} / \mathrm{h}$. Figure 4 shows a PL spectrum of $\mathrm{GaN}$ grown under those conditions. Although the spectrum is dominated by the yellow band emission peaking at $2.15 \mathrm{eV}$, the emission is also detected at $3.47 \mathrm{eV}$. In bulk $h-\mathrm{GaN}$, donor bound excitons emit at $3.4709 \mathrm{eV},{ }^{17}$ and therefore, the emission observed in this study will be related to excitons. Further improvement of the PL properties is expected by optimizing the growth conditions.
In summary, $c$-oriented $h$-GaN was successfully grown on the GaAs(001) substrate with the assistance of the AlAs thin layer. The crystallographic relationship between $h$-GaN and GaAs was clarified from the pole figure measured by $\mathrm{x}$-ray diffraction. PL was observed at $3.47 \mathrm{eV}$ and was attributed to excitonic emission.

This work was supported in part by a Grant-in-Aid for Scientific Research from the Ministry of Education, Science, Sports, and Culture. The pole figure measurements were performed using a facility at the Kyoto University Venture Business Laboratory (KU-VBL).

${ }^{1}$ S. Nakamura and G. Fasol, The Blue Laser Diode (Springer, Heidelberg, 1997).

${ }^{2}$ S. Guha and N. A. Bojarczuk, Appl. Phys. Lett. 72, 415 (1998).

${ }^{3}$ A. Strittmatter, A. Krost, M. Straßburg, V. Trück, D. Bimberg, J. Bläsing, and J. Christen, Appl. Phys. Lett. 74, 1242 (1999).

${ }^{4}$ H. Okumura, S. Misawa, and S. Yoshida, Appl. Phys. Lett. 59, 1058 (1991).

${ }^{5}$ F. Hasegawa, M. Minami, K. Sunaba, and T. Suemasu, Jpn. J. Appl. Phys., Part 2 38, L700 (1999).

${ }^{6}$ H. Tachibana, T. Ishido, M. Ogawa, M. Funato, Sz. Fujita, and Sg. Fujita, J. Cryst. Growth 196, 41 (1999).

${ }^{7}$ M. Ogawa, M. Funato, T. Ishido, Sz. Fujita, and Sg. Fujita, Jpn. J. Appl. Phys., Part 2 39, L69 (2000).

${ }^{8}$ D. Shikora, M. Hankeln, D. J. As, K. Lischka, T. Litz, A. Waag, T. Buhrow, and F. Henneberger, Phys. Rev. B 54, R8381 (1996).

${ }^{9}$ Thermo-Physical Properties of Matter, of T.P.R. Data Series Vol. 13, edited by Y. S. Touloukian, R. K. Kirby, R. E. Taylor, and T. Y. Lee (Plenum, New York, 1977).

${ }^{10}$ Landolt-Börnstein, edited by O. Madelung (Springer, New York, 1982), Vol. 17.

${ }^{11}$ A preliminary calculation showed that the observed crystallographic rela-

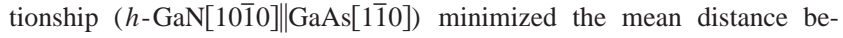
tween GaN and AlAs lattice points at early stages of the growth. This suggests that strain as well is minimized by $h-\mathrm{GaN}[10 \overline{1} 0]|| \operatorname{GaAs}[1 \overline{1} 0]$.

${ }^{12}$ L. A. Kolodziejski, T. Sakamoto, R. L. Gunshor, and S. Datta, Appl. Phys. Lett. 44, 799 (1984).

${ }^{13}$ N. Otsuka, L. A. Kolodziejski, R. L. Gunshor, S. Datta, R. N. Bicknell, and J. F. Schetzina, Appl. Phys. Lett. 46, 860 (1985).

${ }^{14}$ L. A. Kolodziejski, R. L. Gunshor, N. Otsuka, X.-C. Zhang, S.-K. Chang, and A. V. Nurmikko, Appl. Phys. Lett. 47, 882 (1985).

${ }^{15}$ T. Ishido, M. Funato, A. Hamaguchi, Sz. Fujita, and Sg. Fujita (unpublished).

${ }^{16}$ Direct growth of $\mathrm{GaN}$ on $\mathrm{GaAs}$ above $700{ }^{\circ} \mathrm{C}$ resulted in a phase mixture. Therefore, the two-step growth was adopted.

${ }^{17}$ C. Kirchner, V. Schwegler, F. Eberhand, M. Kamp, K. J. Ebeling, K. Kornitzer, T. Ebner, K. Thonke, R. Sauer, P. Prystawko, M. Leszczynski, I. Grzegory, and S. Porowski, Appl. Phys. Lett. 75, 1098 (1999). 